\title{
Network Diagnostics for Rapid Testing, Mapping and Bioinformatics Analysis of SARS-CoV-2 and Other Human Respiratory Viruses in Pandemic Settings
}

This paper was downloaded from TechRxiv (https://www.techrxiv.org).

\section{LICENSE}

CC BY 4.0

SUBMISSION DATE / POSTED DATE

$10-06-2021 / 16-06-2021$

\section{CITATION}

Hossain, Md Arafat (2021): Network Diagnostics for Rapid Testing, Mapping and Bioinformatics Analysis of SARS-CoV-2 and Other Human Respiratory Viruses in Pandemic Settings. TechRxiv. Preprint. https://doi.org/10.36227/techrxiv.14762106.v1

$\mathrm{DOI}$ 


\title{
Network Diagnostics for Rapid Testing, Mapping and Bioinformatics Analysis of SARS-CoV-2 and Other Human Respiratory Viruses in Pandemic Settings
}

\author{
Md Arafat Hossain, Member, IEEE, Barbara Brito-Rodriguez, Lisa M Sedger* \\ and John Canning ${ }^{*}$, Member, IEEE
}

\begin{abstract}
The SARS-Coronavirus-2 (SARS-CoV-2) infectious disease COVID-19 has spread rapidly, resulting in a global pandemic with significant mortality. The combination of early diagnosis via rapid screening, contact tracing, social distancing and quarantine has helped to control the pandemic, and even eliminate the virus in certain countries. A global event of this nature produces immense pressures on diagnostic testing capabilities in all countries and the amounts of diagnostic data allows for nation-wide and global bioinformatics analysis that can yield significant insights into national and global aspects of the pandemic. As such, gold standard molecular diagnostic tests using laboratory methods of PCR (and sequencing) and/or ELISA (serology) require equipment and skilled laboratory scientists but are quickly stretched beyond normal capacity. The absence of real time response and diagnosis is a crucial technology shortfall. In contrast, current information technology offers consumer-engaged smartphone-based "lab-in-a-phone" loT connected devices that can provide added capacity for pandemic monitoring, already exploiting the instant global positioning system (GPS) location data for rapid contact tracing. However, conventional PCR testing is slow and remains the determining step. This review summarizes the mechanisms influencing the spread of respiratory viruses and the current laboratory and smartphone-based testing that can be linked as internet-of-things (IoT) network technologies for the detection of viral nucleic acid and virus-specific antibodies. The promise of yet greater integration of both edge and cloud-based connectivity will deliver immediate analysis and direct communications. Novel swarm technologies will map the spread of infectious diseases in real-time, locally, nationally and globally. Coupled with predictive models and machine learning and artificial intelligence, these POC internet-connected testing options transcend conventional contact tracing with individual device diagnostics to create a rapid global network "superinstrument" resilient to individual test and human errors
\end{abstract}

First footnote: the date on which you submitted your paper for review.

M.A. Hossain is with Department of Electrical and Electronic Engineering, Khulna University of Engineering and Technology, Khulna 9203, Bangladesh (email: arafat@eee.kuet.ac.bd)

B. Brito-Rodriguez is a Chancellor's Post-Doctoral Fellow in the i3 Institute, at University of Technology Sydney, Sydney, NSW, Australia; (email: Barbara.BritoRodriguez@uts.edu.au)

L.M. Sedger is with the Faculty of Science at the University of Technology Sydney, Sydney, Australia. (email: lisa.sedger@uts.edu.au)

J. Canning is with the interdisciplinary Photonic Laboratories (IPL), Global Big Data Technologies Centre (GBDTC), Faculty of Engineering \& Information Technology, University of Technology Sydney, NSW, Australia. (e-mail: john.canning@uts.edu.au) that will disrupt pandemic assessment, treatment and containment saving the lives of millions. For this to evolve, globally agreed to universal standards of testing, measurement protocols and data handling including methods guaranteeing consumer (patient) privacy and confidentiality.

Index Terms - Antibody test, antigen test, bioinformatics, COVID-19, coronavirus, internet-of-things, lab-in-a-phone, LAMP test, next generation sequencing, point-of-care test, PCR, smartphone sensing, rapid diagnostics, SARS-CoV, ethics, privacy.

\section{INTRODUCTION}

A novel respiratory disease caused by the severe acute respiratory syndrome Coronavirus-2 (SARS-CoV-2) was first reported in Wuhan China, in December 2019 [1], producing the World Health Organization (WHO) defined "coronavirus infectious disease of 2019" or COVID-19 [2]. The SARS-CoV-2 virus quickly spread, both within China and internationally causing a global pandemic; by April 04, 2021, WHO estimates suggest that at least 130 million people worldwide have been infected [2]. This markedly contrasts with other human coronaviruses that circulate frequently in humans causing upper respiratory tract infection but with milder symptoms - primarily fever, sniffles, cough and sore throat [3]. Instead, the SARS-CoV-2 virus causes both upper and lower respiratory tract infections and further infects other tissues to cause diverse pathologies and systemic inflammatory immune responses referred to as a "cytokine storm" where high levels of inflammatory cytokines are generated [4]. Thus, the pathobiology of SARS-CoV-2 infection is considerably more complex than in infection with seasonal coronaviruses. Disturbingly, it includes blood clotting events, an autoimmune response similar to Kawasaki disease in infected children [5] and it is particularly virulent in people over 50 years of age and particularly in males [6]. High mutation rates are particularly worrisome with the age and severity greatly expanding the longer it is allowed to transmit freely. Fortunately, doctors have quickly learnt about COVID-19 and optimal treatments in different patient cohorts are presently resulting in higher survival rates.

An understanding of the major transmission mechanisms of SARS-CoV-2 has helped to mandate effective control measures. The virus is primarily spread by respiratory droplet and aerosol particles [7], leading to recommendations for health 
care workers (most at risk) to use N95 masks, and for social distancing and home quarantine - when symptomatic. Clearly, the need for high speed accurate diagnostic tests for COVID19, along with traditional laboratory testing methods, underpins the success of these control measures. Moreover, although the origins of the SARS-CoV-2 virus are not definitively determined beyond high nucleic acid homology with existing bat coronaviruses with a presumed spill over event from bats to humans (or through an intermediate animal species [8]) realtime diagnostics for virus detection, infection monitoring, and disease transmission control is the challenge of this generation, possible given the current technological capabilities and global information technologies. Here, we (i) review the major mechanisms of SARS-CoV-2 transmission, (ii) compare traditional and smartphone-based "lab-on-a-phone" technologies in development for COVID-19 diagnosis and (iii) consider how health informatics influences pandemic monitoring and containment, proposing the concept of novel swarm diagnostics. Already a range of rapid diagnostics platforms have been rapidly developed and are commercially available as point-of-care (POC) tests for clinicians (for reviews see [9-12]). However, the global proliferation of smartphones offer a new platform for simultaneously detecting the infection, tracking movements and assessing people-to-people interactions $[13,14]$. The immediate benefits are many, and their implementation within the community means a symptomatic patient can immediately self-quarantine - an instant major public health advantage by limiting the movement of the infectious individual. Thus, we review these technologies, and the related issues of data confidentiality, for their wide-spread use in pandemic settings.

\section{TESTING IN THE CONTEXT OF RESPIRATORY VIRUS TRANSMISSION}

Worldwide it is generally accepted that there are a high number of SARS-CoV-2 infected individuals who are either asymptomatic or who experience symptomatic disease. The estimated total number of COVID-19 cases therefore depends on both testing rates and on the percentage of both symptomatic and asymptomatic infected people coming forward for testing. False negative test results represent an additional barrier, for several reasons. First, infected patients usually require two to three days before the virus infection is symptomatic (usually evident as upper respiratory tract symptoms). Second, some patients remain asymptomatic and/or harbour very low levels of virus, persistently testing negative for several days postinfection [15]. Thirdly, the test assay performance is critical when considered across large-scale human populations; i.e. testing is unlikely to ever be $100 \%$ reliable and so protocols considering this are important. When considering who may be infected, and for how long they may be nucleic acid test negative, one needs to understand physically and statistically how the virus spreads. This is because both the nature of the infective agent (in this case an RNA virus) and the environment it occupies (indoors/outdoor air, in various moisture levels, on different surface types, or after surface cleaning) are factors that influence infection transmission. Indeed, there are a number of physical transmission vectors that underpin the time-frames of statistical certainty in detecting the respiratory viruses addressing these factors alone is a primary way to contain disease spread. These include the following key vectors:

(i) Water Vapour, Droplets and Aerosols. Emitted airborne water droplets or atmospheric droplets are relatively large and generally fall to the ground or onto surfaces $\leq 2 \mathrm{~m}$. Droplets then survive on surfaces for days to months [16]. Immediately avoiding these infectious droplets is in part the basis for physical distancing as an infection control measure. (Distance varies from $1 \mathrm{~m}$ to $1.5 \mathrm{~m}$ depending on country-specific recommendations). Regular hand washing is also an effective measure that reduces droplet-based infection from fomites. Wearing masks in public locations, and especially on public transport, has additionally proven to be a low-cost control measure that reducing virus spread by droplets and fomites. However, whilst initially effective, complacency often gradually undermines these distancing measures and often trigger so-called waves. This effect is often magnified once the pandemic is perceived as being "under control" and reporting indicates lower infection rates. Smaller droplets, termed aerosols, of $1 \mu \mathrm{m}$ or less are also present in human breath. Aerosols are spherical in shape due to surface tension arising from dipole alignment of water, both actual and instantaneous (or van der Waals) on the droplet surface, which creates a quasiself-aligned charged surface resistant to evaporation. Thus, aerosols can last for extended periods and resist evaporation, particularly in slow moving or still air - explaining the concept of "drop lifetimes" both in air and on surfaces. These can be transmitted beyond $2 \mathrm{~m}$ through air conditioning and ventilation and is always an underestimated course of infection in policy design because of its intractable nature outside of isolation.

A respiratory virus particle can be present both within water droplets and in or on aerosols. (Note: a virus is not often present as a particle in air, but it usually exists within or upon a water droplet or aerosol). It is not known, however, whether the virus can survive for longer within the droplet, or on the surface of the droplet, and little is known about the effect of the charge potential at the water droplet interface and how it effects the virus particle; an air-water interface is charged differently to the droplet surface interface [17]. Other component substances, such as mucus, means that the drop is not actually an "idealized" water drop, but a complex drop, with variable properties that contribute to droplet lifetimes. Other factors are also at play, such as rapid drying of surfaces that accelerates droplet denaturing, or humidity that will prolong droplet longevity and viability.

Whether in droplets, or aerosols, masks function to protect from respiratory spread viruses, in several ways. A mask should ideally be comprised of three layers, each achieving different functions: the innermost layer limits expelled virus (from the infected person), whilst the outer layer acts as a hydrophobic surface repellent (after charging its electrostatic surface exploiting the attraction/repulsion of the aerosol's charge), thus masks reduce the potential reception of virus-laden droplets by the receiver. Inner layers through electret generation draws water away from the surfaces and helps to capture smaller drops that might otherwise pass through the mask pores. A new generation of masks is exploring the potential of added antivirals and disinfectants (within the central layers); i.e. to 
disrupt the viral material and render it uninfectious [18]. It is worth pointing out that simple three-layer cotton masks work surprisingly well because the fibres swell to help reduce gaps when moisture is absorbed, an alternative blocking approach.

(ii) Surface spread of fomites. Contaminated surfaces occur where water droplets and aerosols reach surfaces, and depending on the hydrophilicity/hydrophobicity of the surface, a virus that is present within the water vapour is deposited onto the surface. Viruses only replicate within an infected host cell (in this case a human or animal cells) but can exist - without replicating - on a surface, for days, or months [16]. In theory simple viruses can last forever if the environment is cold and unchanging, a reason why cold transport of COVID-19 cannot be ruled out. As surfaces differ, so too does the potential for long- or short- term virus existence. Smooth solid surfaces such as stainless steel (e.g. door handles) and optically clear materials (e.g. glass or clear plastic face shields) have different hydrophobic and hydrophilic properties to rough surfaces and this in turn impacts viral drying rates.

Water assembly processes at the surface-water interface and the relative van der Waals electrostatic binding determines the longevity of a water droplet or aerosol on the surface. Water can form stable atomic level interfacial surface layers and exist there for long periods, even days, at room temperature, and even after the bulk of the droplet has evaporated [19]. Although the role of these layers in preserving or repelling viruses, and other microbial pathogens, has not been well defined, these layers can theoretically be rapidly removed by heating to $40{ }^{\circ} \mathrm{C}$ [17]. This means that high temperature blow dryers could be used to quickly dry and denature certain viruses that may have been present on the surface - high temperature prevents blowing the droplets elsewhere.

Whilst most solutions for surface contamination are aimed at keeping droplets off the surface [20], risking aerosol regeneration, an alternative is to treat the surface to attract water droplets. This facilitates further spreading over the surface or within a porous surface coating to help dry and either denature on the surface or entrap a virus within. An additional inclusion of a disinfectant (anti-viral or anti-microbial) agent to the surface coating may render a surface deposited-virus uninfectious to human cells. Given that the SARS-CoV-2 virus human receptor is the ACE-2 protein, protein mini-domains could theoretically be used as a viral attractant trap within mask layers, or on critical surfaces such as stainless steel-door handles. A challenge with this approach is ensuring potency with surface cleaning and sufficiently long lifetimes with respect to out-diffusion of the anti-viral agents. Several different protein micro-domain attractors would be required for each different respiratory-spread virus.

SARS-CoV-2 infected humans shed the virus in their faeces [6] so both faecal and respiratory derived droplet/aerosols provide an avenue for fomite-based human-human transmission of the virus [21]. This was evident in the earlier SARS-CoV-1 outbreak, where aerosolised virus-contaminated faecal content drove the spread of the virus within the Amoy Gardens highrise apartment complex in Hong Kong. Plumbing designs and engineering for the use of a water trap (disconnecting the continuity of the sewage drainage and floor drain systems) can prevent fecal-aerosol spread of fecal-shed coronavirus [22].
Nevertheless, the presence of coronaviruses in faeces is an important aide to pandemic infection tracing. In Sydney, Australia, and other places around the world, sewage surveillance is used to identify community persistence of the virus, even amidst a period when zero daily new cases are recorded [23]. The virus detected in sewage may no longer be intact and so not infectious, but nevertheless, the presence of virus fragments of nucleic acid reflects virus shed by infected individuals so the virus remains present within a community.

\section{DIAGNOSTICS}

Unlike SARS-CoV-1 it is possible that SARS-CoV-2 remains an ongoing human respiratory pathogen [24]. In this scenario, a range of SARS-CoV-2 virus diagnostics will continue to be required to identify newly infected people, and to confirm vaccine efficacy - the development of a virusspecific immune responses. Here, we review the principles of the SAR-CoV-2 POC and rapid testing capabilities.

\section{A. Virus nucleic acid tests}

Nucleic acid tests directly detect the presence of a virus genome. For SARS-CoV-2, the genome is RNA which can be extracted from respiratory secretions present on nasopharyngeal swab samples (Figure 1A and B). Saliva at the back of a throat can also be tested using throat swabs [25]. These samples are analysed using three main methods:

(i) The Polymerase chain reaction (PCR). A standard PCR assay copies and amplifies the DNA and is the "gold standard" for virus genome detection. For RNA viruses, such as influenza, and SARS-CoV-2, the process starts with a reverse transcription reaction, converting a single strand of RNA into a complimentary copy of single strand DNA (cDNA). This is followed by amplification of the newly generated DNA template and creating a double stranded DNA (dsDNA) PCR product (Figure 1). In PCR, the repeated iterations amplify the cDNA up to $2^{40}$ times (using 40 or more cycles) producing high yields of the cDNA PCR product that can be visualized, quantified and sequenced. Each PCR "cycle" involves $T=95^{\circ}$ $\mathrm{C}$ denaturing to separate the dsDNA strands with subsequent annealing $\sim T=(50-60){ }^{\circ} \mathrm{C}$ (depending on the oligonucleotide primer sequence). The virus nucleic acid-specific single stranded DNA oligomer anneals to the complementary (targeted) viral genome template. Finally, an elongation step at $T=72^{\circ} \mathrm{C}$ allows the polymerase to amplify the template cDNA. This process is repeated, which logarithmically amplifies the cDNA, $\sim 40+$ times. Thus, the PCR offers high accuracy and sensitivity detection.

To facilitate detection of the PCR-produced nucleic acid, fluorescence marking is employed. A fluorochrome molecule is chemically linked to the PCR primer and a third fluorescentlabelled nucleic acid primer can be included to act as a "probe". Its sequence matches and binds internally within the amplified cDNA PCR product [26]. Alternatively, the PCR reaction can be performed in the presence of a DNA intercalating fluorescent molecule which produced a fluorescent cDNA PCR product [27]. Fluorescence enables faster and more accurate quantifica- 

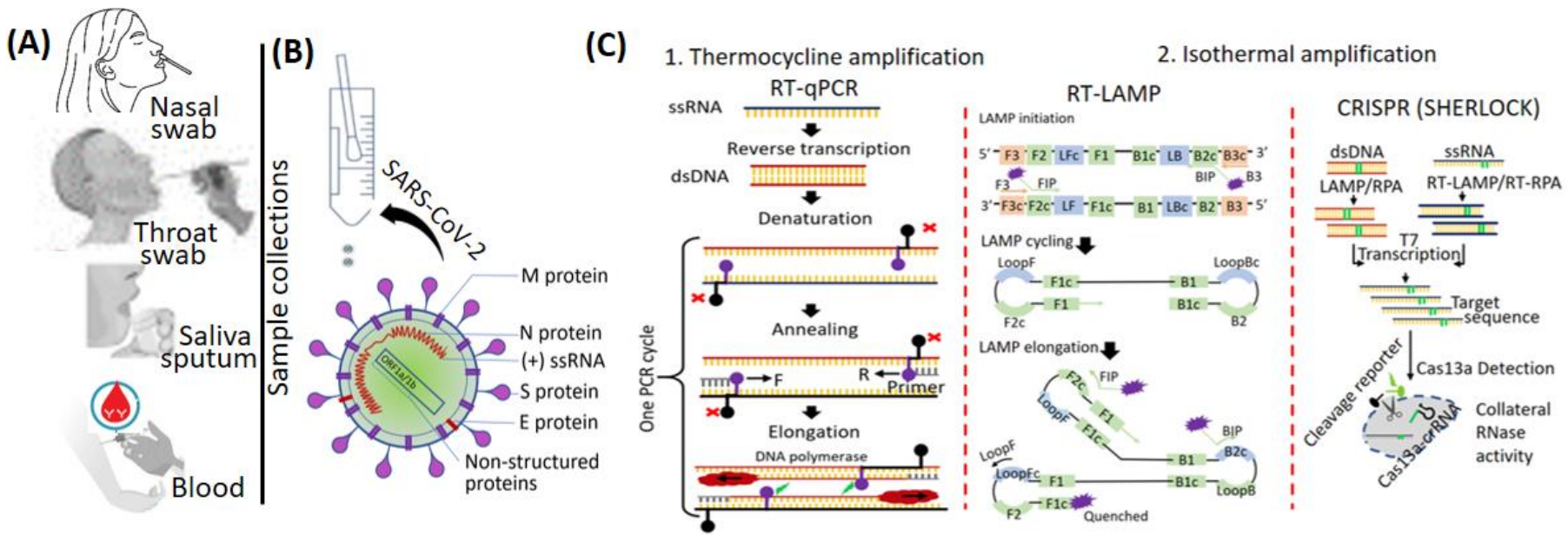

Figure 1. Schematic of current diagnostic methods for viral DNA detection. (A) Sampling from suspected cases or patients and common specimens. (B) Collected samples and structure of the SARS-CoV-2 virus. (C) Mechanisms of the COVID-19 diagnosis using nucleic acid-based tests RT-PCR, RT-LAMP \& the CRISPR (SHERLOCK) systems.

tion of the DNA produced in the PCR reaction with each cycle of PCR and is referred to as "real-time" PCR" or quantitative PCR (qPCR).

A positive PCR test detects the actual virus genomic (RNA or DNA) providing proof of the presence of the virus particle [27]. Confidence is achieved through quality-control considerations such as (1) inclusion of a "no reverse transcriptase" reaction (from the extracted swab nucleic acid) yielding no PCR product, (2) inclusion of PCR reactions targeting multiple separate virus genes (3 separate viral genes) are amplified within each test). Sequence analysis of the PCR product verifies the identity of the amplified nucleic acid. A range of RT-PCR kits for SARS-CoV-2 RNA detection are commercially available. In practice, when new viruses emerge the PCR test will be developed "in house" in clinical microbiology departments and the primer sequences quickly shared internationally, establishing a standardized assay. Nevertheless, knowledge of the virus genome sequence is a necessity a priori for any PCR test.

(ii) Loop-mediated isothermal amplification (LAMP). An adaptation of the PCR is the LAMP method that amplifies the viral RNA or DNA at a constant temperature. This removes the need for a thermocycler, although the same three steps of nucleic acid amplification remain (Figure 1C). LAMP uses DNA polymerase with high strand displacement and replication activity and 2 "inner" primers and "outer" primers that each recognizes separate regions on the target nucleic acid. The LAMP reaction is complete when all primers are correctly annealed to the template, achieving a high specificity reaction, reportedly with fewer false positive results [28]. The amount of DNA produced in LAMP reactions is higher than many conventional PCR reactions and the results can be visible to the naked eye [29-31]. The detection sensitivity is improved by a customized chip to integrate rapid nucleic acid extraction based on an immiscible phase filtration method assisted by surface tension and digital isothermal amplification [32].

(iii) CRISPR-based SHERLOCK system. The clustered, regularly interspaced, short palindromic repeats (CRISPR) family of enzymes such as Cas9, Cas12 and Cas13 have been adapted for use in virus detection, including for SARS-CoV-2 $[33,34]$. The method relies on the endonuclease activity of the CRISPR enzyme after it binds to a specific target RNA via a guiding (programmable) RNA. The Cas-enzymes then cleave the template RNA. The inclusion of a specific reporter molecule releases a detectable signal providing utility as a diagnostic. Specific high sensitivity enzymatic reporter unlocking or "SHERLOCK" is one such assay, reportedly achieving attomolar sensitivity, and single-based mismatched nucleic acid specificity [35] (Figure 1C). Moreover, this assay can be read using a dipstick within around 40 minutes [36]. Recently, SARS-CoV-2 was detected from CRISPR-Cas13a assay of nasal swab RNA read using a smartphone microscope [37].

\section{B. Nucleic acid sequence analysis and bioinformatics}

Next generation sequencing (NGS) platforms permit highdepth sequencing of nucleic acid to obtain complete viral genomes. The short-read sequencing technologies has several advantages including high throughput and high cost efficiency. Illumina sequencing platforms are popular, relying on a reversible fluorescent dye terminator to identify each nucleotide in a DNA strand. At the beginning of an epidemic "shotgun metagenomics" can identify the presence of an unexpected or novel genetic material; i.e. samples from patients with a disease of unknown cause (Figure 2A). This approach consists of fragmenting all of the DNA (or RNA) present in a sample and sequencing it without the need to specify a "target" sequence when it is effectively unknown. It was successfully used to identify the SARS-CoV-2 RNA virus genomes in pneumonia patients in Wuhan, China, as early as December of 2019 [38, 39]. The approach has also been successfully used internationally to sequence viruses from bats and other diverse wildlife species in an attempt to understand the origins of SARS-CoV-1 and SAR-CoV-2 pandemics [40-42].

In contrast, directed genome sequencing approaches are useful during the pandemic for routine sequencing of hundreds of SARS-CoV-2 genomes from infected patients (Figure 2B). The output from these NGS sequencing platforms are short 
sequence data "reads" that are then assembled (i.e. the short reads are joined into longer sequences of overlapping sequences) generating contiguous ("contigs") sequence data. These sequences are then compared with existing sequence databases for taxonomic classification and identification of the responsible organism (Figure 2A). The output reads can then be directly compared to a known reference sequence, both to guide the mapping of the short sequence reads and to obtain the viral genome sequence from a patient's sample (Figure 2B).

NGS and targeted sequence data deliver an immense viral sequence variant detection capacity that can be used to monitor both prevalence within a population and the spread of the variant viruses, locally and globally (Figure 3 ). The factors driving variant emergence remain a separate virological issue but functionally their impact ranges from potential immune escape (evasion of an otherwise effective antibody or $\mathrm{T}$ cell immune response, including vaccine, enhancing virulence) or resistance to a particular anti-viral drug. The relatively high virus replication speeds compared to host cell replication means that genetic evolution occurs quickly in a virus, shaped by multiple host, environment and medication exposure. From an epidemiological perspective, knowledge of virus genome sequence and variants permits the tracking of disease spread within populations. This information is used to determine the index cases during specific local outbreaks and to inform public health responses. In Australia, for example, SARS-CoV-2 sequence data from local community transmission was linked to imported cases in quarantine hotels. This led to a review of the protocols to better contain unintentional community spread.

The sequence analysis and bioinformatics is compiled from data gathered globally and shared at centralized repositories such as NCBI GenBank or GISAID [43, 44]. To date GISAID has received $>$ 991K SARS-CoV-2 genomes sequences from samples internationally (by April 5, 2021). Some countries such as the UK have advanced centres for genomic epidemiology and are actively tracking SARS-CoV-2 molecular evolution: a phylogenetic analyses (Figure 3A). One popular platform used to display the evolution of the virus in space and time in

\section{Nucleic acid extraction}

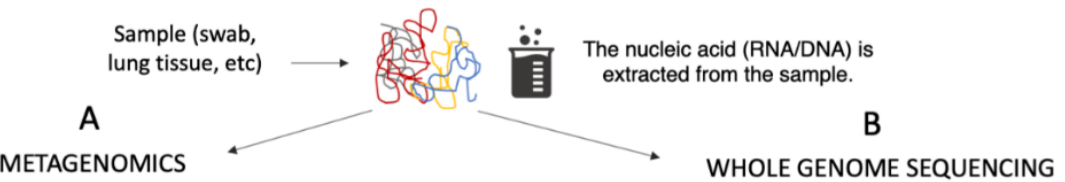

I. Fragmentation and library preparation

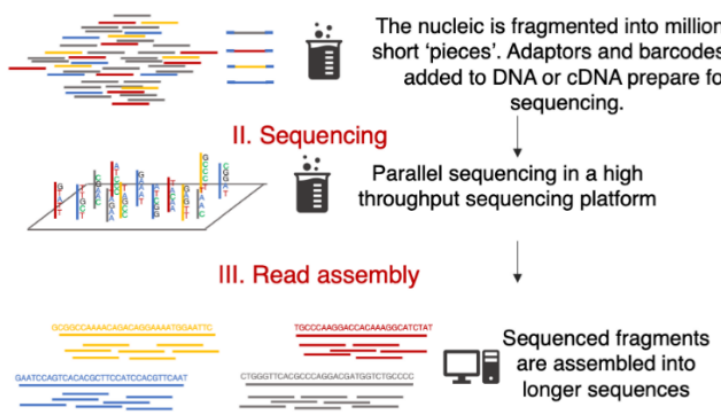

IV. Taxonomic classification
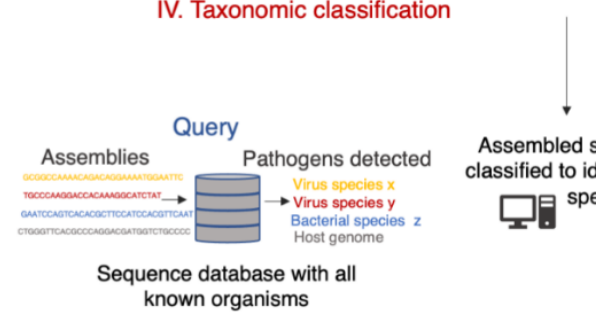

Assembled sequences are classified to identify microbial $\square$. species known organisms

- SARS-CoV-2 was identified as a novel virus causing a cluster of pneumonia in Wuhan.

- Novel viruses from wildlife species can be sequenced

I. Amplification of the desired target (SARSCoV-2 genome)
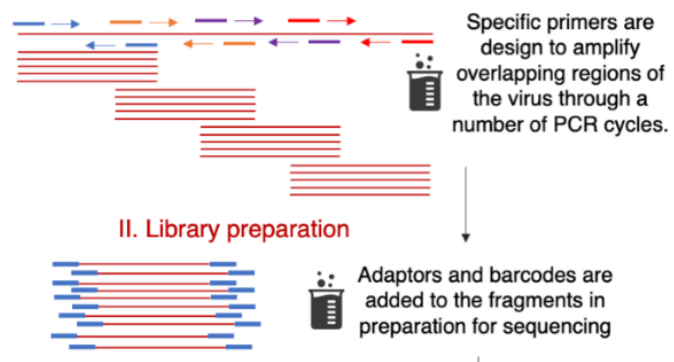

III. Sequencing
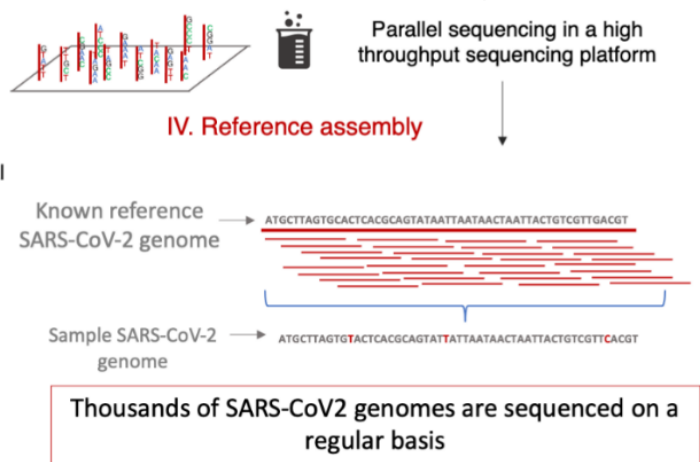

Figure 2: Next generation sequencing technologies applications during the SARS-CoV-2 pandemic. A. Metagenomics approaches used at the beginning of the SARS-CoV-2 epidemic to investigate the causal agent of a cluster of "novel" pneumonia cases, in Wuhan, China. Extraction of nucleic acid, fragmenting and amplifying the nucleic acid fragments, then adding "adaptors" that permit the fragments bind to a flow cell in the NGS platform. All fragments are sequenced in parallel, and detected by different fluorescent signals emitted by the four nucleotides: A, T, G, C. The sequence for all fragments is assembled to generate a contiguous "reference" sequence. The sequences are then queried against existing reference databases. This permits the taxonomic classification and identification of genomic species. B. Whole genome sequence of SARS-CoV-2 also begins with nucleic acid extractions, then amplifying selected targeted genome regions with specific oligonucleotide primers that bind to overlapping regions of the viral genome. This PCR product is sequenced in the flow cell. Because SARSCoV-2 genomes are similar, the assembly is guided by mapping all the sequenced reads to a reference sequence. A consensus of these references is then obtained as one linear sequence from a patient's sample. 
Nextstrain [45]. However, other platforms have been developed to identify lineages and variants [46]. The UK variant B.1.1.7 was flagged in December of 2019 as a potential highly transmissible "more fit" virus after observing that its frequency of detection was rising much faster than other lineages [47], on its way to becoming dominant. Thus, bioinformatics platforms can identify if a sequence from a patient belongs to a particular variant group (i.e. a specific outbreak). This is important both for understanding the virus and for considering vaccine efficacy (against variants).

\section{Antibody tests}

Antibody tests provide evidence of current versus prior infection by detecting the presence of specific antibody molecules in the blood. An antibody, or immunoglobulin (Ig) as it is also known, is a multi-chain protein molecule (it has two heavy chains and two smaller or light chains held together by disulfide bonds). The combined heavy and light chain region binds to "antigens" with high specificity and high affinity.

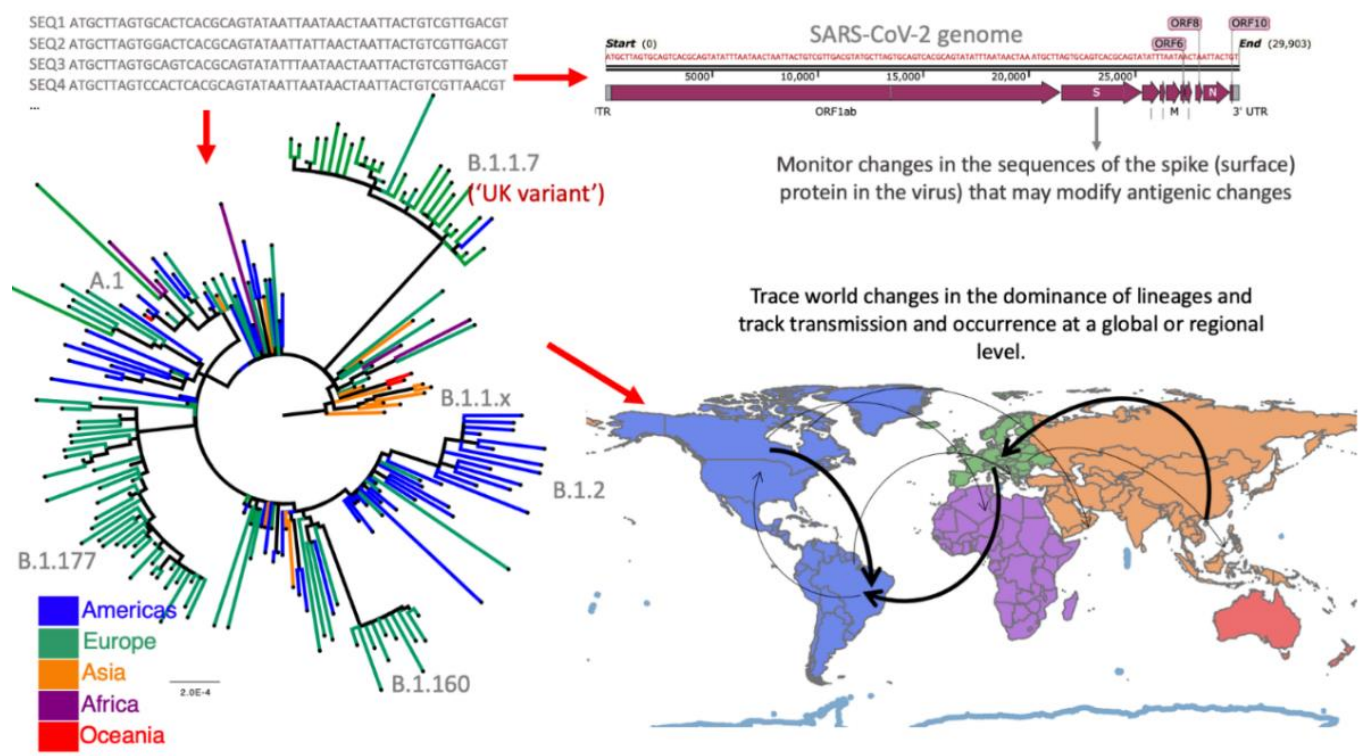

Figure 3. Uses of viral genetic sequence data. With the thousands of sequences obtained globally, phylogenetic trees are constructed to understand the evolutionary relationship of the viral genomes. When integrating this information with the epidemiological data (for example, the sample's location of origin and day in which the sample is collected) maps that illustrate the virus spread and evolution can be generated. Tracking new lineages or sequence variants (viruses that are genetically related and that group in a branch of the phylogenetic tree) can help the early detection of a potentially highly transmissible or more virulent form of the virus. For example, the specific changes in a viral spike protein sequence can be monitored - the spike protein is the viral surface protein engages with a host cell receptor molecule. The viral spike is recognized by the host immune system antibodies that confer immunity. Therefore, tracking changes in the spike protein sequence identifies the evolution of the virus with respect to its antigenic properties and even the capacity of vaccines to confer immunity - protection capability. The phylogenetic tree in the image was constructed using 200 random samples from GISAID database, IQ-TREE [48] with the GTR + F + R2 substitution model. The map was created in QGIS [49] and the genome map was created using SnapGene [50].

Other regions with the antibody molecule mediate several effector functions such as binding to Fc-receptors highly expressed by phagocytic macrophages and natural killer cells to facilitate phagocytosis of the virus (i.e. immune system removal of the virus) as well as killing of the virus infected cells. When a B lymphocyte produces an antibody, it first produced an IgM antibody. It then changes its heavy chain to create another antibody molecule, an IgG, with the same specificity to the antigen - so called "isotype switching". During this process, the antigen affinity is retained and the specificity further increased. Thus, mammals first produce IgM antibodies during the initial response to a virus infection, then subsequently, an isotypeswitched IgG. Detection of IgM and IgG antibodies therefore indicates a current infection, whereas, detection of IgG only (and low or no IgM) indicates a more distant or past infection.

Antibody molecules are detected by an enzyme-linked immunosorbent assay (ELISA). There are several versions of this assay. Most commonly, a purified protein or whole microbe is bound to a well of a 96-well flat bottom plastic dish. A "blocking" step using low fat (skim) milk or $1 \%$ bovine serum albumin prepared in saline to bind to any residual plastic surfaces not already covered by the microbial antigen. In the next step, patient serum (usually with several serial dilutions) is added to the wells of the 96-well dish. If a virus-specific antibody is present in the serum, then it will bind to the antigen coating the wells. In the final steps a detection method is used to demonstrate that an antibody has bound to the antigen. Usually detection involves another, second antibody with specificity for either human IgM or IgG. This detection antibody also has an enzyme chemically conjugated to it. The addition of the enzyme substrate permits a color reaction that can be read both visually or by a spectrophotometer. Colorimeter results are reported as positive (color) and negative (no color). If serum dilutions are assayed, then the amount of antibody yielding a positive result can be quantified as a "titre"the dilution at which the absorbance is greater than 3 standard deviations above the mean of the wells with no serum: the dilution of serum that produced the lowest clearly positive result. Alternatively, the readout can simply be relative to the extent of color development: an absorbance reading (at the appropriate wavelength for the enzyme substrate color). Carefully performed, ELISA assays can demonstrate increase 
or decrease in the amount of a pathogen-specific IgM and $\operatorname{IgG}$ so the assay is quantitative. As well as providing a temporal infection clock, antibody testing identifies people who have recovered from COVID-19 and have protective antibodies. These individuals may be eligible to donate their blood for clinical use as convalescent plasma to treat others with severe life-threatening disease [51, 52].

ELISA tests are typically performed with blood samples. Collection of the test sample therefore requires the minor discomfort of phlebotomy and therefore also requires a person skilled in phlebotomy. However, an antibody test can identify asymptotic cases of COVID-19 by detecting their immune response (antibody) [53]. Similarly, ELISA assays can determine persons who are now fully recovered and who have eliminated the virus but still have plasma antibodies. Since they no longer harbor the virus the PCR test will be negative. ELISA assays are relatively inexpensive but their major disadvantages include: (i) requiring an invasive blood sample, (ii) need for trained laboratory personnel to perform the assay, and (iii) producing the antigen in a form that binds to the ELISA plate.

Significant advancements to the ELISA test have seen innovative antibody-based tests come to market in recent years. Many of these tests have been developed as POC items for consumer use for the diagnosis of pandemic or seasonal influenza and now also for COVID-19 [54, 55]. Below we summarize the current POC and smartphone-connected antibody-based technologies.

(i) Lateral flow tests. A lateral flow test or device can also detect the presence of antibodies in plasma. It uses a paper-like membrane strip coated with two-lines: gold nanoparticleconjugates are present in one line and capture antibodies in the other line [56]. The patient's sample is deposited on the membrane and the target antibodies are drawn with capillary action across the strip (Figure 4). As the sample diffuses past the first line, the antibodies bind to the gold nanoparticles and the conjugate flows through the membrane. As it reaches the second line, the conjugate is immobilized by the enzymeconjugated capture antibodies, and a red or blue line becomes visible after substrate is produced. Individual gold nanoparticles are red, but a solution containing clustered gold nanoparticles is blue (due to coupling of the plasmon bands). Appearance of the color indicates a positive test, while an additional color line (control line) confirms the validity of the test (Figure 4A). These assays are often semi-quantitative in that the quantity of the detected antibody is determined by the color intensity, although the color is currently measured subjectively (visually). This feature can result in variability in operator; a color-blind person could find distinguishing the color difficult and the test is unusable by a blind person. As a colorimetric tool they are, however, ideally amenable to smartphone analysis removing much of this human error.

The main benefits of lateral flow tests are their ease of use by non-skilled persons and the quick incubation time $(<30$ mins $)$. Lateral flow tests are frequently referred to as "rapid diagnostic tests" or RDT as they constituted 38\% of the FDA approved antibody tests developed within the first six months of the SARS-CoV-2 pandemic [57]. Several innovations have resulted smartphone-based lateral flow device detection methods (Figure 4B). The test data can be communicated and collated with cloud-based connection of analyzers [58-60].

(ii) Microfluidics assays. In a microfluidic device, the color is produced in a reflecting path on a transparent substrate to improve signal-to-noise levels. Some complex microfluidic structures make use of 3D-printable transparent polymers such as polymethyl methacrylate (PMMA) [61]. The digital assay applies an electromagnetic field to manipulate and mix individual droplets on a superhydrophobic plate (reducing the risk of physical contamination). For low-cost, flexible operation outside the laboratory, paper-based analytical devices can be more suitable than polymer-based microfluidic chips because they are flexible, easily handled, stored and disposed [62].

Issues of false-positive or false-negative test rates remain, but the high specificity and affinity of antibody molecules reduce these possibilities. The primary disadvantage is related to sensitivity of the small sample quantity being tested. This finite small volume confers several limitations. For example, when low virus (antigenic) is loaded, the antibody detection molecule may never "see" or interact with it. Also, if allowed to "float" within the sample chamber, there is a statistical hit and miss ratio that worsens with decreasing concentration or perhaps counterintuitively, with increased volumes. Thus, attempts to amplify the signal are being considered by using fluorescence and chemiluminescence $[75,76]$. Here, a small fluorescent molecule (a fluorophore, fluorescent protein, or a quantum dot) that emits photons after excitation from laser or broad-spectrum light is used. Although the detection requires an excitation light source and an emission filter and photodiode or CMOS chip, highly-sensitive fluorogenic detection has been developed for the detection of antibodies specific to zika virus, chikungunya virus, and dengue virus using a two-stage LAMP-based microfluidic nucleic acid detection [63].

The limit of detection is currently at the level of single copy of nucleic acid in PBS and 10 copies of viral genetic material in human serum [63]. The sensitivity can be increased by using 3D membrane filters capable of rapid and multi-fold analyte capture, or simply delivering more capture antibody. Electrochemical biosensors are being developed that produce an electrical signal or an optical emission (electroluminescence). The electrical signal is directly plugged into a portable display device or a camera can be used to detect the luminescent output and data is digitised. The assay performs well in comparison with other clinical methods. Gold electrodes functionalized with self-assembled thiol chemical groups have been used to detect zika virus DNA in a device that measures impedance changes [64]. Electrode capacitance has also been used to detect dengue virus antigen-antibody complexes [65].

\section{SMARTPHONE BASED RAPID DIAGNOSTICS}

During infectious disease pandemics rapid testing, preferably real-time, delivers the critical means by which symptomatic people can confirm the identity of an infection without overwhelming the clinical laboratory capacity for traditional PCR or antibody ELISA testing. However, a key limitation with rapid testing is both test measurement and result interpretation errors. The transport of data and results is also problematic today. There is a need for real-time testing and tracking in the field to ideally link to cloud-based analysis and diagnosis. 

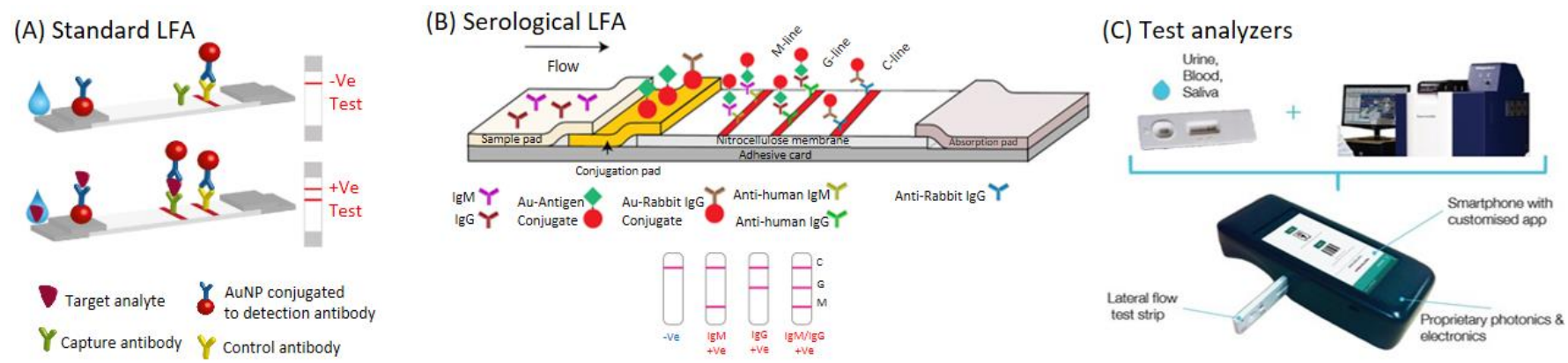

Figure 4. Lateral flow-based detection devises. (A) General immunoassay technique using rapid diagnostic lateral flow assay (Image reproduced from [66] permission is not required). (B) A smartphone analyser for lateral flow tests reduces a large benchtop instrument into a portable hand carried device that automatically collects data and sends into the cloud. (Images C courtesy of AusSI Systems).

Given the widespread prevalence of smartphones, this would be the current platform of choice. The smartphone itself can act as the diagnostic instrument. Moving the data instantly into the cloud into monitoring databases allows instant disease identification (perhaps against known tabulated records) and notification locally, nationally or globally via mobile networks (Figure 5). Automated data collection in the "cloud" is achieved through edge sensors that transmit data to wireless base stations and from there via fibre optic cable into the cloud and to other points of analysis. Whilst the smartphone is typically transmitting in RF or mm domain (from $3 \mathrm{G}$ to $5 \mathrm{G}$, and by $\sim 2030$ 6G, depending on location), the sensor itself may be decoupled and transmit data to the smartphone. This would ideally use customized protocols tailored for short distance transmission of low-level quantities of data in different environments in order to reduce interference and improve privacy and connection security.

The quality of guaranteed data transmission is an ongoing concern since not all countries globally have well embedded internet networks and the capacity for large volumes may overwhelm such networks if not managed appropriately. The absence of global standards and agreements will remain the single largest factor that prevents future network instruments that are integrated with informatics. Nonetheless, within certain domains demonstrations of this capability are becoming evident. For example, in the US FDA approved heart ECG monitors exist and function well with long-distance patient data studies over time [67]. A broader global effort for use of such technology is being undermined by a growing global divide concerned with ethics and where some societies are attempting to establish separate controlled internets, an approach that has probably contributed to the persistent culture of unsatisfactory information disclosure during the current and recent pandemics. This type of test data transmission needs further careful consideration with respect to privacy issues. Improved data security is therefore critical to maintaining confidentiality. Other issues include whether data is shared and how - across state or country borders - as well as the issue of ownership of the electronic data. The WHO have recommended that a global diagnostics internet be centralized and administered by a universally accepted authority [68]. Within the major telecommunication societies, the acceptance of universal privacy and ethics is a recognised concern. Field-accessible, mobile, smart-sensing capabilities exist $[69,70]$. Hopefully, the global SARS-CoV-2 / COVID-19 pandemic will accelerate these developments.

(i) Smartphone based nucleic acid tests. The necessary components for sample collection, genome extraction, amplification and signal processing within an integrated device for use in the field already exist. For example, extraction of the virus genetic material (from respiratory samples) can be driven by a low-power fan mounted onto the smartphone platform, providing a centrifugal force-based extraction [71]. For a "fieldfunctional" operation, an in-flight drone centrifuge and convective PCR on smartphone might be employed [72]. The nucleic acid test itself can be performed based on RayleighBernard natural convection for buoyancy-driven thermal gradients of liquid heating [73-75]. Heating occurs from the bottom of the reaction, meaning a spatial temperature gradient established between the top (cool) and the bottom (hot) surfaces of the reactor, simulating a thermocycler. Convection movement of solutions is the driving force that physically transports reagents between the reaction zones. Other variations use renewable energy sources such as solar heat radiations to actuate the reactions [76, 77]. A self-contained platform has been reported that explores capability for a smartphone device that performs both temperature tuneable and time-resolved fluorescence measurements with continuous photographic and self-controlled timing of the detector $[78,79]$. There are already a number of reports of rapid isothermal amplification for COVID-19 diagnosis [80, 81]. One system utilizes a hot coffee mug to provide the temperature for the RT-LAMP reaction for colorimetric detection of zika virus (ZIKV) RNA in human urine and saliva samples [82]. The device uses an innovative ball-based valve which enables the storage and sequential delivery of reagents in a paper-based unit within the mug for RNA enrichment and purification. Another reactor design with water-triggered exothermic material offers a low-cost SmartCup for energy efficient reactions [83]. LAMP reactions are also possible on microfluidic paper integrated with a smartphone-based fluorescent reader [84-87]. Microfluidic integration can be multiplexed to include multiple reactions to detect different viruses [87-89]. A silicon microfluidic chip containing 10 parallel flow channels has been developed for multiplexed LAMP detection of bacterial and viral pathogens [87] - a smartphone camera captures the fluorescence readout.

For NGS, analysis of the sequence reads is generally performed using dedicated high-end server computers, or cloud services, which require massive machine to machine (M2M) data transfer through a broadband network. MinION is a 


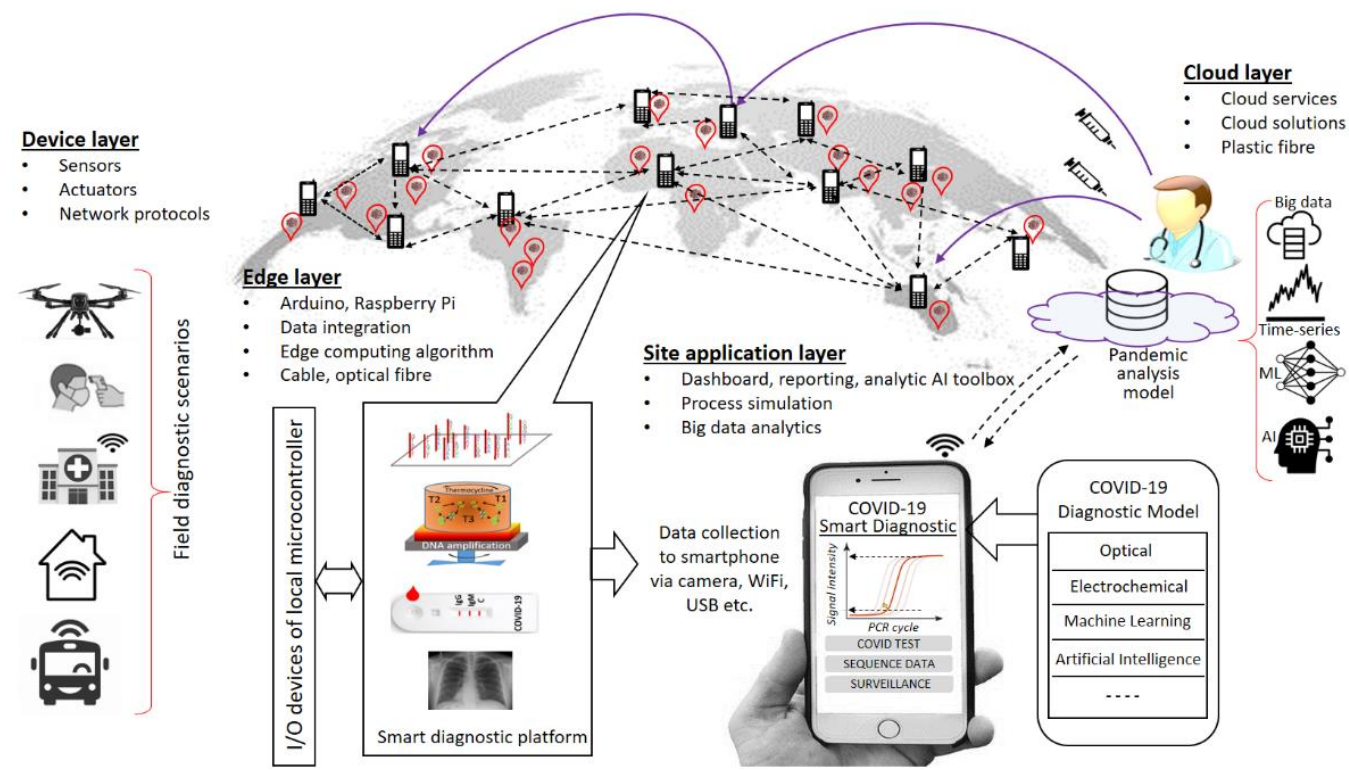

Figure 5. Transmission networks underpin the internet and cloud-based diagnostics and informatics capabilities. Diagnostics at the devices layer feeds into the cloud via the edge using various transmission capabilities such as wireless and optical fibres. Alternatives exist for how data can be transferred. The results are collected at a central server from detection sites by the sensor devices which are used to analyze sequence, predict virus types using $\mathrm{Al}$ and develop a suitable vaccine which can be prescribed to the afftected sites.

compact device that uses similar technology that has become popular due to its portable size allowing sequencing in the field [90]. Edge analysis greatly reduces bandwidth so smartphone applications have been used to perform a range of bioinformatic sequence data analyses from sequence alignments to variant detection [91]. Near-real time sequence data analyses is essential for clinician's and epidemiological data tracking [14].

(ii) Smartphone-based antibody tests. The digitization of the antibody colorimetric test results, albeit on a test strip, or an ELISA plate, has long been part of the results output [92-95]. Several commercial bodies are aiming to develop single-use, disposable device, serological testing for SARS-CoV-2 antibodies using smartphone devices [96]. Typically, the assay integrates smartphone camera imaging for rapid digital quantification of dot-based ELISA [97]. Early assessments suggest these rapid assays can match laboratory grade accuracy. Also, 3D-printing technology has been used to fabricate packaging and customized optics for multiplex ELISA detection with smartphone cameras [98-100]. One drawback of smartphones as a diagnostic is that they do not have a consistent color correction, particularly for multiple color parameters and vary across models [101] raising questions over accuracy and sensitivity. Nonetheless, individual smartphones can be calibrated and performances comparable with benchtop equipment.

With an individual device smartphone detection for avian influenza specific human serum antibodies was achieved with a sensitivity of $96.5 \%$ and a specificity of $98.5 \%$ [102]. In another example, a smartphone camera images the fluorescent labelled secondary antibodies in barcode-like patterns upon the recognition of the virus [88]. In these examples, the optics for excitation requires an additional external power source typically, a monochromatic light source requires a heavy power supply (e.g. a rechargeable battery) which limits POC portability. For some cases, it is possible that an excitation source can be powered by smartphone in-built rechargeable battery or a USB connection to an external hard-wired power supply [69, 103]. Furthermore, electrochemical biosensors generate an electrical signal output, or a luminescent emission [104-108]. The output electrical signal can be directly plugged into the smartphone via its micro-USB port and a luminescent output can be detected via the camera with subsequent digitizing of the output information, and indeed, several microcontroller platforms have delivered affordable electrochemical biosensors this way [104]. A geno-sensor has been designed for the differential detection of ZIKV infection and its discrimination from other human flavivirus infections such as dengue virus [105]. In this example, the sensor captures signal probes and PCR amplify the target genetic material. Similarly, an electrochemical impedance sensor imprinted onto a traditional lateral flow strip is reported for portable quantitative detection of ZIKV [106]. The impedimetric sensor uses a micro-electrode of gold immune-sensing chip which was prepared via immobilization of ZIKV specific envelop protein antibody [106]. A portable platform has been developed to perform some of the more common electroanalytical techniques of chronoamperometry, differential pulse voltammetry and square wave voltammetry [107].

\section{EMERGING TECHNOLOGIES}

There are a broad range of exciting new technologies being developed for rapid testing applications including the SARSCOV-2 diagnosis. These are summarized below and in Table I.

(i) Optical technologies. A number of photonic based methods are being applied to sensing and diagnostics. For example, a localized surface plasmon resonance (SPR) biosensor has been developed for the detection of SARS-CoV-2 virus [109]. The sensor uses $2 \mathrm{D}$ gold nano-islands that make up the plasmonic material functionalized with cDNA probes. These probes recognise specific SARS-CoV-2 RNA genomic sequences of 
TABLE I: Innovative technologies for detection \& informatics analysis of COVID-19 \& diseases.

\begin{tabular}{|c|c|c|c|}
\hline Detection methi & Target & Prospects & Constraints \\
\hline \multicolumn{4}{|c|}{ Section A: Nucleic acid testing } \\
\hline $\begin{array}{l}\text { Smartphone } \\
\text { RT-qPCR }\end{array}$ & $\begin{array}{l}\text { DENV DNA [110] } \\
\text { Avian influ. DNA [74] } \\
\text { Salmonella DNA [111] } \\
\text { Human 18S ribosomal RNA } \\
\text { [112] }\end{array}$ & $\begin{array}{l}\text { - Digital quantification makes multiplexed } \\
\text { detection and identify co-infections } \\
\text { - 3D-printable, auto sample injection and control } \\
\text { - Smartphone processing and real-time reporting, } \\
\text { faster than clinical diagnosis }(<1 \mathrm{hr}) \\
\end{array}$ & $\begin{array}{l}\text { - Thermal instability, power } \\
\text { requirement and complex } \\
\text { - Need interfaces of genome } \\
\text { collection and extraction } \\
\text { - Dependence of viral load } \\
\end{array}$ \\
\hline $\begin{array}{l}\text { Smartphone } \\
\text { convective } \\
\text { PCR }\end{array}$ & $\begin{array}{l}\text { H1N1 influenza-A RNA [74] } \\
\text { S. aureus DNA [72, 75] } \\
\text { E. coli O157:H7 DNA [71] }\end{array}$ & $\begin{array}{l}\text { - Buoyancy driven natural convection } \\
\text { - Less power and electronic control } \\
\text { - On-board genome extraction using miniature } \\
\text { fan/drone-based centrifuge }\end{array}$ & $\begin{array}{l}\text { - Open-loop temperature control } \\
\text { - Lack of integrated sample } \\
\text { preparation capability }\end{array}$ \\
\hline $\begin{array}{l}\text { Solar thermal } \\
\text { PCR }\end{array}$ & $\begin{array}{l}\text { Kaposi's Sarcoma herpesvirus } \\
\text { DNA [76] }\end{array}$ & $\begin{array}{l}\text { - Solar heating for PCR thermocycling } \\
\text { - Low power ( } 80 \mathrm{~mW}) \text {, fast response }(<30 \mathrm{~min}) \\
\text { - Smartphone based fluorescence detection }\end{array}$ & $\begin{array}{l}\text { - Limited lifetime (phone battery) } \\
\text { - Temperature adjustment } \\
\text { needed for weather variation }\end{array}$ \\
\hline $\begin{array}{l}\text { Smartphone } \\
\text { LAMP }\end{array}$ & $\begin{array}{l}\text { ZIKV RNA [82] } \\
\text { Herpes simplex virus DNA [83] } \\
\text { SARS-CoV-2 RNA [81] } \\
\text { Influenza-A H1N1, S. aureu } \\
\text { [80] } \\
\text { P. falciparum DNA [84] } \\
\text { HIV RNA; EHV1, EHV4 and EIV } \\
\text { DNA [87]; ZIKV, DENV, CHIV } \\
\text { RNA [85] }\end{array}$ & $\begin{array}{l}\text { - Fixed and relatively lower T requirement } \\
\text { - Multiple primers increase specificity } \\
\text { - Innovative designs of reaction chamber (e. g. } \\
\text { SMART cup/mug) allow storage and sequential } \\
\text { delivery of reagents, RNA enrichment and } \\
\text { purification, exothermic chemical reaction } \\
\text { - Easy to handle and dispose for faster POC test } \\
\text { such as with smartphone set up (30 } 40 \text { mins) }\end{array}$ & $\begin{array}{l}\text { - Need an RNA extraction kit } \\
\text { - Multiple primers and regent } \\
\text { costs }\end{array}$ \\
\hline CRISPR & crRNA of SARS-CoV-2 [34] & $\begin{array}{l}\text { - Ultra-sensitivity, specificity and accuracy } \\
\text { - Colorimetric and fluorescence readouts } \\
\text { - Capable of handling many samples at a time } \\
\text { - No need of RNA separation and amplification }\end{array}$ & $\begin{array}{l}\text { - Limits uses at the patient's end } \\
\text { as it needs skilled operators }\end{array}$ \\
\hline \multicolumn{4}{|c|}{ Section B: Antigen or Antibody Testing } \\
\hline $\begin{array}{l}\text { Smartphone } \\
\text { immunoassay } \\
\text { tests (LFA, } \\
\text { ELISA, ECL) }\end{array}$ & $\begin{array}{l}\text { HIV/syphilis IgM /or IgG [113] } \\
\text { Influenza-A [97] } \\
\text { Avian influenza H5N3, H7N1 \& } \\
\text { H9N2 [102] } \\
\text { CD4 test of HIV [114] } \\
\text { Type-I pyrethroids in } \\
\text { pesticides [115] }\end{array}$ & $\begin{array}{l}\text { - Low-power, ultra-portable with low-cost PAD } \\
\text { - On-chip sample collection and purification with } \\
\text { less hardware, user intervention and regent cost } \\
\text { - Space and wavelength division multiplexed } \\
\text { detections using smartphone optical readout } \\
\text { - Rapid detection (10-30 mins) including } \\
\text { asymptomatic carriers, site identification, } \\
\text { geographical transmission and past infection } \\
\text { - Comparable to clinical ELISA: sensitivity }>90 \%) \\
\text { specificity }>80 \% \text { and accuracy }>95 \%\end{array}$ & $\begin{array}{l}\text { - Does not always show active } \\
\text { infection } \\
\text { - Variation of antibody levels: } \\
\text { suffers sensitivity issue at the } \\
\text { beginning of infection } \\
\text { - Misleading results due to cross- } \\
\text { reactivity with antibodies of } \\
\text { similar coronaviruses } \\
\text { - Many are yet to show } \\
\text { effectiveness in COVID-19 }\end{array}$ \\
\hline $\begin{array}{l}\text { Optical } \\
\text { interferomet- } \\
\text { ry }\end{array}$ & $\begin{array}{l}\text { RNA/Antigen of SARS-CoV-2 } \\
\text { [120] }\end{array}$ & $\begin{array}{l}\text { - Ultra-fast optical detection (6-10 minutes of viral } \\
\text { RNA hybridization) } \\
\text { - Reduced false negative results } \\
\text { - Demonstrated for SARS-CoV-2 detection }\end{array}$ & $\begin{array}{l}\text { - Packaging and stability are } \\
\text { difficult }\end{array}$ \\
\hline $\begin{array}{l}\text { Al-based } \\
\text { imaging }\end{array}$ & Patient lung image $[121,122]$ & $\begin{array}{l}\text { - Portable X-ray, CT, digital microscopy tools } \\
\text { - Advanced computer vision, machine learning } \\
\text { algorithms improves detection accuracy } \\
\text { - Smart health system management and control }\end{array}$ & $\begin{array}{l}\text { - Insufficient data to train } \\
\text { algorithm } \\
\text { - Security, privacy issues } \\
\text { - Low specificity of imaging tests. }\end{array}$ \\
\hline
\end{tabular}

the virus and are attached to gold nanoparticles by hybridization. Two complementary strands of DNA are hybridized when the temperature is below the melting point [109]. Plasmonic nanoparticles within the surface plasmon excitation region have broad optical cross-sections coupled to non-radiative decay that produce highly localised heat upon optical absorption. This local heat is adjusted to make it more difficult for imperfectly matched sequences, compared to the desired target, thereby reducing false-positive readings. In another SPR-based sensor, a metal-coated optical fibre generates a propagating plasmonic surface wave at the interface. This measures changes in the refractive index of the environment being analyzed [123]. Here, the refractive index change occurs with a virus antigen or antibody interaction, producing a change in the output optical signal. The level of sensitivity of the detection can be improved by using 3Dprinted novel fibres that increase surface interactions with the analytes [124, 125] as well as using other fibre optic resonant components such as Bragg gratings [126]. Highly sensitive detection can also be achieved using an optical interferometric biomedical waveguide interference between two optical modes [127]. The visible light interacts with analytes during 
propagation and the output interference is recorded using a photodetector array. The optical detection of SARS-CoV-2 coronavirus can be accelerated by combining the magnetic affinity of nanoparticles into the detection system [128]. This technique uses the virus RNA specific fluorescent probe that attaches to the virus RNA and emits light when illuminated by a laser. With the use of magnetic particles that adhere to the fluorescent molecules, a magnetic field drives their movement in the solution and aggregation in the laser beam illuminating area helping to amplify signal strength. This technique can potentially detect ultra-low viral RNA concentrations [129].

Optical imaging modalities (chest X-ray and CT scans) were initially used to diagnose the infection in Wuhan hospital [122]. The only issue here is that $\mathrm{CT}$ scan results are often nonspecific with respect to infectious agent, although they can illustrate the physiological location by identifying viral-induced damage such as lung and respiratory tract inflammation. In the future, in situations where clinicians are unavailable such as in rural locations, or even in overly busy central hospitals, machine learning, possibly AI which is often confused with machine learning, might triage the incoming data to categorise patients relative to the limited available resources in pandemic settings. The initial challenge is access sufficient realistic clinical data for algorithm training and to test and verify high accuracy.

(ii) Nanomaterials and nanotechologies. Nanomaterials such as graphene or silicene, within nanodevices such as field-effect transistors (FETs) based transducers can be used as bioreceptors for antigen or antibody detection with high sensitivity [118]. These materials can act as the channel within a fluid environment and as a liquid gate, where the channel material surface is attached with a sample under test. For example, a SARS-CoV spike glycoprotein S1 subunit specific antibody, or spike host cell receptor (ACE2) protein has been attached by non-covalent crosslinking to graphene [116, 117, 119]. These combined organic electrochemical materials can be integrated as channels with nanostructured isoporous membranes customized for high affinity to viral proteins [130].

(iii) Smart fabrics and wearables. Smart textiles design and treatments with anti-viral agents can create an invisible coating that inhibits viral sustainability. Coatings that can repel liquids and potentially prevent viruses from adhering to the surface have also been demonstrated [20]. For example, silver-based technologies can destroy enveloped viruses including coronaviruses by $99.99 \%$ [131] and a "disinfectant velvet" has been developed that is capable of photocatalysis when exposed to UV light [11]. In other approaches, ultra-thin skin-like patches with infra-red temperature sensors can be integrated into wearables such as shirts, helmets, googles and watches for monitoring temperature as a correlate of potential infection (i.e. symptoms of fever) [132] and automatic alarms can be built-in when diagnoses thresholds are breached. Although exciting, a degree of caution is required, because the degree of accuracy of these detection fabrics is yet to be properly investigated.

(v) Real-time bioinformatics capabilities. Once infectious disease test data, including NGS data, can be collected in real time, this offers the capacity for direct immediate informatics analysis, nationally or globally. For example, automation and linking rapid diagnostics, permits comparisons to pre-existing reference data including virus nucleic acid genome sequences, instantaneously via cloud connectivity. This increases the value of the data by reducing translation times and reducing the potential for data errors that may be present in large field data streams (i.e. having arisen from human involvement or from long sample transport times). These communication networks allow for direct linkages to be made in all directions simultaneously, because the big data analytics behind the bioinformatics occurs in real-time, with immediate return of results back to the field. This offers a new paradigm for informed immediate disease control. Moreover, it provides equity in access to global healthcare advisors, not otherwise possible.

This level of real-time communication permits quick translation of optimal treatment regimes, for example, for distinct viral variants (Figure 5). Thus, critical result outcomes are shared equitably, irrespective of the location of any infected patient. Such data utilization taking advantage of smartphone tracking has already been tested in respiratory virus epidemics situations. The British Broadcasting Corporation documentary "Pandemic" described the situation where a smartphone app was launched in a 2018 influenza epidemic for a citizen science experiment. Some 28,965 people volunteered, providing their contact data and movement data - collected by GPS - from different patches across the UK, transmitted to a central server and applied in a timeseries analysis to determine the incidence cases and origins of the infection [14]. Two different scenarios were studied: (1) the start of the outbreak within a local town (Haslemere in Surrey; withinpatch), and (2) the spread of the pandemic through the UK (between-patches). The analysis used a discrete-time (susceptible people - infectious people - recovered people) SIR model to determine the output parameters that considers the user profile, their movement, encounter times, relative transmission coefficient and basic reproduction ratio comparable with a similar virus outbreak [133]. Although this analysis did not explicitly include the mortality rate, it has successfully demonstrated how the extra control measures can considerably slow down an infectious outbreak to reduce the impact. It is entirely conceivable that additional physiological information such as an individuals' body temperature, could potentially be observed from an elevated surveillance thermal camera. Hence the connection of diagnostic test information with real-time mapping, maximized the usefulness of the data. A cloud-based analysis of this type can assist with a targeted response action towards individuals even within a crowd setting.

All informatics is highly dependent on the quality of the direct measurement. In this sense, perhaps machine learning or AI can be invaluable to accelerate and automate analysis within increasing accuracy in diagnosis of infection level (mild, moderate, severe) [134]. Thus, coupling AI to cloud based interconnectedness of instant data, globally, could allow for a comprehensive informatics analysis that is unmatched today. Already, a neural network framework through deep learning has shown COVID-19 prediction accuracy of $82 \%$ using smartphone sensor measurements [135]. Whilst bioinformatics is still in its infancy, the spread of smartphone detection instrumentation and edge processing, coupled with swarm technologies means implementation of mass data analytics in real-time is near. 


\section{CONCLUSIONS}

SARS-CoV-2 testing and control measures can be significantly improved with ongoing development of networked POC devises, smartphone technologies and global internet- and cloud- based bioinformatics. Whilst the POC device will likely never directly replace gold-standard laboratory PCR testing as a standalone technology, together with the convergence of these technologies the POC test offers immediacy and accessibility for more people than would otherwise be tested. Through this connectivity combined with informatics, the network diagnostic circumvents the problem of individual test inaccuracy. Therefore, the test of choice in the future will be more about those tests that can be integrated in volume into a hardware driven real-time informatics network diagnostic where increasingly edge computation as well as cloud analytics relying on collective data

\section{REFERENCES}

[1] K. G. Andersen et al. "The proximal origin of SARS-CoV-2," Nature Medicine, vol. 26, no. 4, pp. 450-452, Apr. 2020.

[2] WHO Coronavirus Disease (COVID-19) Dashboard [Online]. Available: https://covid19.who.int/

[3] A. Sette and S. Crotty, "Pre-existing immunity to SARS-CoV-2: the knowns and unknowns," Nature Reviews Immunology, vol. 20, no. 8, pp. 457-458, Aug. 2020.

[4] Y. Tang et al."Cytokine Storm in COVID-19: The Current Evidence and Treatment Strategies," Front Immunol, Review vol. 11, no. 1708, p. 1708, Jul. 2020.

[5] L. Verdoni et al., "An outbreak of severe Kawasaki-like disease at the Italian epicentre of the SARS-CoV-2 epidemic: an observational cohort study," Lancet, vol. 395, no. 10239, pp. 1771-1778, Jun. 2020.

[6] J. B. Dowd et al., "Demographic science aids in understanding the spread and fatality rates of COVID-19," Proceedings of the National Academy of Sciences, vol. 117, no. 18, p. 9696, May 2020.

[7] J. W. Tang et al. "Introduction of the South African SARS-CoV-2 variant 501Y.V2 into the UK," The Journal of infection, pp. S01634453(21)00030-X, Jan. 2021.

[8] D. Cyranoski, "Mystery deepens over animal source of coronavirus," Nature, vol. 579, no. 7797, pp. 18-19, Mar. 2020.

[9] L. J. Carter et al., "Assay Techniques and Test Development for COVID19 Diagnosis," ACS Central Science, vol. 6, no. 5, pp. 591-605, May 2020.

[10]F. Cui and H. S. Zhou, "Diagnostic methods and potential portable biosensors for coronavirus disease 2019," Biosens Bioelectron, vol. 165, p. 112349, Oct. 2020.

[11]M. Raeiszadeh and B. Adeli, "A Critical Review on Ultraviolet Disinfection Systems against COVID-19 Outbreak: Applicability, Validation, and Safety Considerations," ACS Photonics, vol. 7, no. 11, pp. 2941-2951, Nov. 2020.

[12]B. Udugama et al., "Diagnosing COVID-19: The Disease and Tools for Detection," ACS Nano, vol. 14, no. 4, pp. 3822-3835, Apr. 2020.

[13]I. G. Cohen, L. O. Gostin, and D. J. Weitzner, "Digital Smartphone Tracking for COVID-19: Public Health and Civil Liberties in Tension," JAMA, vol. 323, no. 23, pp. 2371-2372, May 2020.

[14]P. Klepac, S. Kissler, and J. Gog, "Contagion! The BBC Four Pandemic The model behind the documentary," Epidemics, vol. 24, pp. 49-59, Sep. 2018.

[15]L. M. Kucirka et al. "Variation in False-Negative Rate of Reverse Transcriptase Polymerase Chain Reaction-Based SARS-CoV-2 Tests by Time Since Exposure," Annals of Internal Medicine, vol. 173, no. 4, pp. 262-267, Aug. 2020.

[16]S. Riddell, S. Goldie, A. Hill, D. Eagles, and T. W. Drew, "The effect of temperature on persistence of SARS-CoV-2 on common surfaces," Virology Journal, vol. 17, no. 1, p. 145, Oct. 2020.

[17]J. Canning, "Water photonics, non-linearity, and anomalously large electro-optic coefficients in poled silica fibers," MRS Communications, vol. 8, no. 1, pp. 29-34, Feb. 2018.

[18]H. Huang, H. Park, Y. Liu, and J. Huang, "On-Mask Chemical Modulation of Respiratory Droplets," Matter, vol. 3, no. 5, pp. 1791-1810, Nov. 2020.

[19]J. Canning, "Optical hoovering on plasmonic rinks," MRS Communications, vol. 9, no. 3, pp. 1072-1078, Jul. 2019. can potentially offer resilience over test accuracy whilst predicting disease spread and impact customised for any environment. Further, this new direction will change and shape the future of pandemic assessments because pandemics are global and their spread is determined by environmental factors. They therefore require a global "super diagnostic" that has not yet been available. Given the shortfalls in addressing livability and the environment [136], a global network "super diagnostic" instrument will be critical in identifying and neutralizing future disease before it becomes a pandemic and rapidly containing that which has. Importantly, consumer smartphones capable of computing at the network edge presently stand out in their ability to engage and involve the consumer with ease in this battle against viruses.

[20]A. J. Galante, S. Haghanifar, E. G. Romanowski, R. M. Q. Shanks, and P. W. Leu, "Superhemophobic and Antivirofouling Coating for Mechanically Durable and Wash-Stable Medical Textiles," ACS Applied Materials \& Interfaces, vol. 12, no. 19, pp. 22120-22128, May 2020.

[21]F. Xiao, M. Tang, X. Zheng, Y. Liu, X. Li, and H. Shan, "Evidence for Gastrointestinal Infection of SARS-CoV-2," Gastroenterology, vol. 158, no. 6, pp. 1831-1833 e3, May 2020.

[22]K. R. McKinney, Y. Y. Gong, and T. G. Lewis, "Environmental transmission of SARS at Amoy Gardens," J Environ Health, vol. 68, no. 9, pp. 26-30; quiz 51-2, May 2006.

[23] Status of environmental surveillance for SARS-CoV-2 virus, Scientific Brief [Online]. Available: https://www.who.int/newsroom/commentaries/detail/status-of-environmental-surveillance-for-sarscov-2-virus

[24]B. Korber et al., "Tracking Changes in SARS-CoV-2 Spike: Evidence that D614G Increases Infectivity of the COVID-19 Virus," Cell, vol. 182, no. 4, pp. 812-827.e19, Aug. 2020.

[25] W. Wang et al., "Detection of SARS-CoV-2 in Different Types of Clinical Specimens," JAMA, vol. 323, no. 18, pp. 1843-1844, Mar. 2020.

[26]I. V. Kutyavin et al., "3'-minor groove binder-DNA probes increase sequence specificity at PCR extension temperatures," Nucleic acids research, vol. 28, no. 2, pp. 655-661, Jan. 2000.

[27]H. D. VanGuilder, K. E. Vrana, and W. M. Freeman, "Twenty-five years of quantitative PCR for gene expression analysis," Biotechniques, vol. 44, no. 5, pp. 619-26, Apr. 2008.

[28]E. L. A. Howson et al., "Defining the relative performance of isothermal assays that can be used for rapid and sensitive detection of foot-and-mouth disease virus," Journal of virological methods, vol. 249, pp. 102-110, Aug. 2017.

[29]L. E. Lamb, S. N. Bartolone, E. Ward, and M. B. Chancellor, "Rapid detection of novel coronavirus/Severe Acute Respiratory Syndrome Coronavirus 2 (SARS-CoV-2) by reverse transcription-loop-mediated isothermal amplification," (in eng), PloS one, vol. 15, no. 6, pp. e0234682e0234682, Jun. 2020.

[30]L. Mautner et al., "Rapid point-of-care detection of SARS-CoV-2 using reverse transcription loop-mediated isothermal amplification (RTLAMP)," Virology Journal, vol. 17, no. 1, p. 160, Oct. 2020.

[31]L. Yu et al., "Rapid Detection of COVID-19 Coronavirus Using a Reverse Transcriptional Loop-Mediated Isothermal Amplification (RT-LAMP) Diagnostic Platform," Clin Chem, vol. 66, no. 7, pp. 975-977, Jul. 2020.

[32]F. Hu et al., "Smartphone-Based Droplet Digital LAMP Device with Rapid Nucleic Acid Isolation for Highly Sensitive Point-of-Care Detection," Anal Chem, vol. 92, no. 2, pp. 2258-2265, Jan. 2020.

[33]J. S. Gootenberg et al., "Nucleic acid detection with CRISPRCas13a/C2c2," Science, vol. 356, no. 6336, pp. 438-442, Apr. 2017.

[34]J. P. Broughton et al., "CRISPR-Cas12-based detection of SARS-CoV-2," Nature Biotechnology, vol. 38, no. 7, pp. 870-874, Jul. 2020.

[35]J. Joung et al., "Point-of-care testing for COVID-19 using SHERLOCK diagnostics," medRxiv : the preprint server for health sciences, $\mathrm{p}$. 2020.05.04.20091231, May 8, 2020.

[36]M. J. Kellner, J. G. Koob, J. S. Gootenberg, O. O. Abudayyeh, and F. Zhang, "SHERLOCK: nucleic acid detection with CRISPR nucleases," Nat Protoc, vol. 14, no. 10, pp. 2986-3012, Oct. 2019. 
[37]P. Fozouni et al., "Amplification-free detection of SARS-CoV-2 with CRISPR-Cas13a and mobile phone microscopy," Cell, vol. 184, no. 2, pp. 323-333.e9, Jan. 2021.

[38]P. Zhou et al., "A pneumonia outbreak associated with a new coronavirus of probable bat origin," Nature, vol. 579, no. 7798, pp. 270-273, Mar. 2020.

[39]L. Chen et al., "RNA based mNGS approach identifies a novel human coronavirus from two individual pneumonia cases in 2019 Wuhan outbreak," Emerging Microbes \& Infections, vol. 9, no. 1, pp. 313-319, Jan. 2020.

[40] V. Hul et al., "A novel SARS-CoV-2 related coronavirus in bats from Cambodia," bioRxiv, p. 2021.01.26.428212, Jan. 26, 2021.

[41]H. Zhou et al., "A Novel Bat Coronavirus Closely Related to SARS-CoV2 Contains Natural Insertions at the S1/S2 Cleavage Site of the Spike Protein," Current Biology, vol. 30, no. 19, p. 3896, Jun. 2020.

[42]T. T.-Y. Lam et al., "Identifying SARS-CoV-2-related coronaviruses in Malayan pangolins," Nature, vol. 583, no. 7815, pp. 282-285, Jul. 2020.

[43]GenBank Overview [Online]. Available: https://www.ncbi.nlm.nih.gov/genbank/

[44] GISAID [Online]. Available: https://www.gisaid.org/

[45]Nextstrain SARS-CoV-2 resources [Online]. Available: https://nextstrain.org/sars-cov-2/

[46] Pango lineages [Online]. Available: https://covlineages.org/pango lineages.html

[47]A. Rambaut. Preliminary genomic characterisation of an emergent SARSCoV-2 lineage in the UK defined by a novel set of spike mutations [Online]. Available: https://virological.org/

[48] J. Trifinopoulos, L.-T. Nguyen, A. von Haeseler, and B. Q. Minh, "W-IQTREE: a fast online phylogenetic tool for maximum likelihood analysis," Nucleic Acids Research, vol. 44, no. W1, pp. W232-W235, Jul. 2016.

[49]QGIS, A Free and Open Source Geographic Information System [Online]. Available: https://qgis.org/en/site/

[50] Insightful Science [Online]. Available: https://www.snapgene.com/

[51]G. Marano et al., "Convalescent plasma: new evidence for an old therapeutic tool?," Blood Transfus, vol. 14, no. 2, pp. 152-7, Mar. 2016.

[52]D. Focosi, A. O. Anderson, J. W. Tang, and M. Tuccori, "Convalescent Plasma Therapy for COVID-19: State of the Art," Clinical Microbiology Reviews, vol. 33, no. 4, pp. e00072-20, Aug. 2020.

[53]R. Li et al., "Substantial undocumented infection facilitates the rapid dissemination of novel coronavirus (SARS-CoV-2)," Science, vol. 368, no. 6490, p. 489, May 2020.

[54]N. Iwanaga et al., "Novel ACE2-IgG1 fusions with improved activity against SARS-CoV2," bioRxiv : the preprint server for biology, $\mathrm{p}$. 2020.06.15.152157, Jun. 15, 2020.

[55]S. Miersch et al., "Synthetic Antibodies neutralize SARS-CoV-2 infection of mammalian cells," p. 2020.06.05.137349, 2020.

[56]E. B. Bahadır and M. K. Sezgintürk, "Lateral flow assays: Principles, designs and labels," TrAC Trends in Analytical Chemistry, vol. 82, pp. 286306, Sep. 2016.

[57]In Vitro Diagnostics EUAs, Coronavirus Disease 2019 (COVID-19) Emergency Use Authorizations for Medical Devices [Online]. Available: https://www.fda.gov/medical-devices/coronavirus-disease-2019-covid19-emergency-use-authorizations-medical-devices/vitro-diagnosticseuas\#individual-molecular

[58]S. K. Vashist, E. M. Schneider, and J. H. Luong, "Commercial Smartphone-Based Devices and Smart Applications for Personalized Healthcare Monitoring and Management," Diagnostics (Basel), vol. 4, no. 3, pp. 104-28, Aug. 2014

[59]J. L. D. Nelis et al., "Smartphone-based optical assays in the food safety field," TrAC Trends in Analytical Chemistry, vol. 129, p. 115934, Aug. 2020.

[60]K. H. Foysal et al. "Analyte Quantity Detection from Lateral Flow Assay Using a Smartphone," Sensors (Basel, Switzerland), vol. 19, no. 21, p. 4812, Nov. 2019.

[61]P.-H. Lu et al., "A structure-free digital microfluidic platform for detection of influenza a virus by using magnetic beads and electromagnetic forces," Lab on a Chip, 10.1039/C9LC01126A vol. 20, no. 4, pp. 789-797, Feb. 2020.

[62] Y. Xia, J. Si, and Z. Li, "Fabrication techniques for microfluidic paperbased analytical devices and their applications for biological testing: A review," Biosensors and Bioelectronics, vol. 77, pp. 774-789, Mar. 2016.

[63]B. S. Batule, Y. Seok, and M.-G. Kim, "Paper-based nucleic acid testing system for simple and early diagnosis of mosquito-borne RNA viruses from human serum," Biosensors and Bioelectronics, vol. 151, p. 111998, Mar. 2020.
[64]H. A. M. Faria and V. Zucolotto, "Label-free electrochemical DNA biosensor for zika virus identification," Biosensors and Bioelectronics, vol. 131, pp. 149-155, Apr. 2019

[65]J. Cecchetto et al., "Serological point-of-care and label-free capacitive diagnosis of dengue virus infection," Biosensors and Bioelectronics, vol. 151, p. 111972, Mar. 2020.

[66]Z. Li et al., "Development and clinical application of a rapid IgM-IgG combined antibody test for SARS-CoV-2 infection diagnosis," Journal of Medical Virology, https://doi.org/10.1002/jmv.25727 vol. 92, no. 9, pp. 1518-1524, 2020/09/01 2020.

[67]R. Bennett and A. French, "Rise of the smart device ECG and what it means for the general cardiologist," Heart, vol. 105, no. 22, p. 1763, Nov. 2019.

[68]WHO, "Increasing access to diagnostics through technology transfer and local production," $20112011, \quad$ Available: https://www.who.int/phi/publications/Increasing Access to Diagnostics Through_Technology_Transfer.pdf, Accessed on: 30 Nov 2020.

[69]M. A. Hossain, J. Canning, S. Ast, K. Cook, P. J. Rutledge, and A. Jamalipour, "Combined "dual" absorption and fluorescence smartphone spectrometers," Opt Lett, vol. 40, no. 8, pp. 1737-40, Apr. 2015.

[70]P. C. Biswas, S. Rani, M. A. Hossain, M. R. Islam, and J. Canning, "Multichannel Smartphone Spectrometer Using Combined Diffraction Orders," IEEE Sensors Letters, vol. 4, no. 9, pp. 1-4, Sep. 2020.

[71]Y. M. Park et al."Multifunctional hand-held sensor using electronic components embedded in smartphones for quick PCR screening," Biosensors and Bioelectronics, vol. 141, p. 111415, Sep. 2019.

[72]A. Priye et al., "Lab-on-a-Drone: Toward Pinpoint Deployment of Smartphone-Enabled Nucleic Acid-Based Diagnostics for Mobile Health Care," Analytical Chemistry, vol. 88, no. 9, pp. 4651-4660, May 2016.

[73]A. Priye and V. Ugaz, DNA-to-go: A portable smartphone-enabled PCR assay platform. 2014.

[74]X. Qiu et al., "A smartphone-based point-of-care diagnosis of H1N1 with microfluidic convection PCR," Microsystem Technologies, vol. 23, no. 7, pp. 2951-2956, Jul. 2017.

[75]V. K. Rajendran, P. Bakthavathsalam, P. L. Bergquist, and A. Sunna, "Smartphone detection of antibiotic resistance using convective PCR and a lateral flow assay," Sensors and Actuators B: Chemical, vol. 298, p. 126849, Nov. 2019.

[76]L. Jiang et al. "Solar thermal polymerase chain reaction for smartphoneassisted molecular diagnostics," Scientific Reports, vol. 4, no. 1, p. 4137, Feb. 2014.

[77]M. Kong et al., "A wearable microfluidic device for rapid detection of HIV1 DNA using recombinase polymerase amplification," Talanta, vol. 205, p. 120155 , Dec. 2019.

[78]M. A. Hossain et al., "Time-resolved and temperature tuneable measurements of fluorescent intensity using a smartphone fluorimeter," Analyst, 10.1039/C7AN00535K vol. 142, no. 11, pp. 1953-1961, Jun. 2017.

[79]Y. Jiang, B. Li, and W. Wu, "Application of automatic feedback photographing by portable smartphone in PCR," Sensors and Actuators B: Chemical, vol. 298, p. 126782, Nov. 2019.

[80]Y.-D. Ma et al., "A sample-to-answer, portable platform for rapid detection of pathogens with a smartphone interface," Lab on a Chip, 10.1039/C9LC00797K vol. 19, no. 22, pp. 3804-3814, Nov. 2019.

[81] M. El-Tholoth, H. H. Bau, and J. Song, "A Single and Two-Stage, ClosedTube, Molecular Test for the 2019 Novel Coronavirus (COVID-19) at Home, Clinic, and Points of Entry," ChemRxiv : the preprint server for chemistry, p. 10.26434/chemrxiv.11860137.v1, Feb 19, 2020.

[82]X. Jiang et al., "Valve-Enabled Sample Preparation and RNA Amplification in a Coffee Mug for Zika Virus Detection," Angew Chem Int Ed Engl, vol. 57, no. 52, pp. 17211-17214, Dec. 2018.

[83] S.-C. Liao et al., "Smart cup: A minimally-instrumented, smartphonebased point-of-care molecular diagnostic device," Sensors and Actuators B: Chemical, vol. 229, pp. 232-238, Jun. 2016.

[84]J. Reboud et al., "Paper-based microfluidics for DNA diagnostics of malaria in low resource underserved rural communities," Proceedings of the National Academy of Sciences, vol. 116, no. 11, p. 4834, Mar. 2019.

[85]A. Ganguli et al., "Hands-free smartphone-based diagnostics for simultaneous detection of Zika, Chikungunya, and Dengue at point-ofcare," Biomed Microdevices, vol. 19, no. 4, p. 73, Aug. 2017.

[86]W. Chen et al., "Mobile Platform for Multiplexed Detection and Differentiation of Disease-Specific Nucleic Acid Sequences, Using Microfluidic Loop-Mediated Isothermal Amplification and Smartphone Detection," Anal Chem, vol. 89, no. 21, pp. 11219-11226, Nov. 2017. 
[87]F. Sun et al., "Smartphone-based multiplex 30-minute nucleic acid test of live virus from nasal swab extract," Lab on a Chip, 10.1039/D0LC00304B vol. 20, no. 9, pp. 1621-1627, Apr. 2020.

[88]J. Kim et al., "Clinical Validation of Quantum Dot Barcode Diagnostic Technology," ACS Nano, vol. 10, no. 4, pp. 4742-4753, Apr. 2016.

[89] Y. Seok et al., "A Paper-Based Device for Performing Loop-Mediated Isothermal Amplification with Real-Time Simultaneous Detection of Multiple DNA Targets," Theranostics, vol. 7, no. 8, pp. 2220-2230, Jul. 2017.

[90]H. Samarakoon et al., "Genopo: a nanopore sequencing analysis toolkit for portable Android devices," Communications Biology, vol. 3, no. 1, p. 538, Sep. 2020.

[91] A. Palatnick et al. "iGenomics: Comprehensive DNA sequence analysis on your Smartphone," GigaScience, vol. 9, no. 12, Dec. 2020.

[92]M. A. Kabir et al. "Development of a Flow-Free Automated Colorimetric Detection Assay Integrated with Smartphone for Zika NS1," Diagnostics (Basel, Switzerland), vol. 10, no. 1, p. 42, Jan. 2020.

[93] A. Priye, C. S. Ball, and R. J. Meagher, "Colorimetric-Luminance Readout for Quantitative Analysis of Fluorescence Signals with a Smartphone CMOS Sensor," Analytical Chemistry, vol. 90, no. 21, pp. 12385-12389, Nov. 2018.

[94]L. Shen, J. A. Hagen, and I. Papautsky, "Point-of-care colorimetric detection with a smartphone," Lab on a Chip, 10.1039/C2LC40741H vol. 12, no. 21, pp. 4240-4243, Oct. 2012.

[95]D. Xu, X. Huang, J. Guo, and X. Ma, "Automatic smartphone-based microfluidic biosensor system at the point of care," Biosensors and Bioelectronics, vol. 110, pp. 78-88, Jul. 2018.

[96]COVID-19 SMARTPHONE TESTING KIT [Online]. Available: https://mobiledetectbio.com/

[97]D. Wu et al., "A paper-based microfluidic Dot-ELISA system with smartphone for the detection of influenza A," Microfluidics and Nanofluidics, vol. 21, no. 3, p. 43, Feb. 2017.

[98] K. D. Long, H. Yu, and B. T. Cunningham, "Smartphone instrument for portable enzyme-linked immunosorbent assays," Biomedical optics express, vol. 5, no. 11, pp. 3792-3806, Nov. 2014.

[99]L.-J. Wang, Y.-C. Chang, R. Sun, and L. Li, "A multichannel smartphone optical biosensor for high-throughput point-of-care diagnostics," Biosensors and Bioelectronics, vol. 87, pp. 686-692, Jan. 2017.

[100] L.-J. Wang et al. "High-Throughput Optical Sensing Immunoassays on Smartphone," Analytical Chemistry, vol. 88, no. 16, pp. 8302-8308, Aug. 2016.

[101] S. Rani, P. C. Biswas, M. A. Hossain, M. R. Islam, and J. Canning, "Polynomial regression of multiple sensing variables for high-performance smartphone colorimeter," OSA Continuum, vol. 4, no. 2, pp. 374-384, Feb. 2021.

[102] S. J. Yeo et al., "Smartphone-Based Fluorescent Diagnostic System for Highly Pathogenic H5N1 Viruses," Theranostics, vol. 6, no. 2, pp. 231-42, Jan. 2016.

[103] A. Hossain, J. Canning, S. Ast, P. J. Rutledge, T. L. Yen, and A. Jamalipour, "Lab-in-a-Phone: Smartphone-Based Portable Fluorometer for $\mathrm{pH}$ Measurements of Environmental Water," IEEE Sensors Journal, vol. 15, no. 9, pp. 5095-5102, Sep. 2015.

[104] G. Vásquez et al. "Amperometric biosensor based on a single antibody of dual function for rapid detection of Streptococcus agalactiae," Biosens Bioelectron, vol. 87, pp. 453-458, Jan. 2017.

[105] D. Alzate et al. "Genosensors for differential detection of Zika virus," Talanta, vol. 210, p. 120648, Apr. 2020.

[106] A. Kaushik et al., "A sensitive electrochemical immunosensor for labelfree detection of Zika-virus protein," Scientific Reports, vol. 8, no. 1, p. 9700, Jun. 2018.

[107] J. T. C. Barragan and L. T. Kubota, "Minipotentiostat controlled by smartphone on a micropipette: A versatile, portable, agile and accurate tool for electroanalysis," Electrochimica Acta, vol. 341, p. 136048, May 2020.

[108] N. Nasir and M. Al Ahmad, "Cells Electrical Characterization: Dielectric Properties, Mixture, and Modeling Theories," Journal of Engineering, vol. 2020, p. 9475490 , Jan. 2020.

[109] G. Qiu et al. "Dual-Functional Plasmonic Photothermal Biosensors for Highly Accurate Severe Acute Respiratory Syndrome Coronavirus 2 Detection," ACS Nano, vol. 14, no. 5, pp. 5268-5277, May 2020.

[110] B. Shi et al. "A handheld continuous-flow real-time fluorescence qPCR system with a PVC microreactor," Analyst, 10.1039/C9AN01894H vol. 145, no. 7, pp. 2767-2773, Apr. 2020.

[111] T. Gou et al., "Smartphone-based mobile digital PCR device for DNA quantitative analysis with high accuracy," Biosensors and Bioelectronics, vol. 120, pp. 144-152, Nov. 2018.
[112] C. D. Ahrberg et al. "Handheld real-time PCR device," Lab on a Chip, 10.1039/C5LC01415H vol. 16, no. 3, pp. 586-592, Feb. 2016.

[113] T. Laksanasopin et al., "A smartphone dongle for diagnosis of infectious diseases at the point of care," Sci Transl Med, vol. 7, no. 273, p. 273re1, Feb. 2015.

[114] M. K. Kanakasabapathy et al., "Rapid, label-free CD4 testing using a smartphone compatible device," Lab Chip, vol. 17, no. 17, pp. 2910-2919, Aug. 2017.

[115] E. Costa, E. Climent, S. Ast, M. G. Weller, J. Canning, and K. Rurack, "Development of a lateral flow test for rapid pyrethroid detection using antibody-gated indicator-releasing hybrid materials," Analyst, 10.1039/D0AN00319K vol. 145, no. 10, pp. 3490-3494, May 2020.

[116] R. Campos et al., "Attomolar Label-Free Detection of DNA Hybridization with Electrolyte-Gated Graphene Field-Effect Transistors," ACS Sensors, vol. 4, no. 2, pp. 286-293, Feb. 2019.

[117] M. T. Hwang et al., "Ultrasensitive detection of nucleic acids using deformed graphene channel field effect biosensors," Nature Communications, vol. 11, no. 1, p. 1543, Mar. 2020.

[118] V. C. Martins et al., "Femtomolar limit of detection with a magnetoresistive biochip," Biosens Bioelectron, vol. 24, no. 8, pp. 2690-5, Apr. 2009.

[119] B. Ibarlucea et al., "Ultrasensitive detection of Ebola matrix protein in a memristor mode," Nano Research, vol. 11, no. 2, pp. 1057-1068, Feb. 2018.

[120] CONVAT project aims for point-of-care Covid-19 diagnosis [Online]. Available: https://optics.org/news/11/4/13

[121] X. Mei et al., "Artificial intelligence-enabled rapid diagnosis of patients with COVID-19," Nature Medicine, vol. 26, no. 8, pp. 1224-1228, Aug. 2020.

[122] W. Yang and F. Yan, "Patients with RT-PCR-confirmed COVID-19 and Normal Chest CT," Radiology, vol. 295, no. 2, p. E3, May 2020.

[123] J. Lu et al., "Immunoassay for Detection of Infliximab in Whole Blood Using a Fiber-Optic Surface Plasmon Resonance Biosensor," Analytical Chemistry, vol. 89, no. 6, pp. 3664-3671, Mar. 2017.

[124] J. Canning, M. A. Hossain, C. Han, L. Chartier, K. Cook, and T. Athanaze, "Drawing optical fibers from three-dimensional printers," Opt Lett, vol. 41, no. 23, pp. 5551-5554, Dec. 2016.

[125] K. Cook et al., "Air-structured optical fiber drawn from a 3D-printed preform," Opt Lett, vol. 40, no. 17, pp. 3966-9, Sep. 2015.

[126] J. Canning, "Fibre gratings and devices for sensors and lasers," Laser \& Photonics Reviews, https://doi.org/10.1002/lpor.200810010 vol. 2, no. 4, pp. 275-289, Aug. 2008.

[127] D. Wrapp et al., "Cryo-EM structure of the 2019-nCoV spike in the prefusion conformation," Science, vol. 367, no. 6483, p. 1260, Mar. 2020.

[128] B. Shmuel et al. "Magnetically aggregated biosensors for sensitive detection of biomarkers at low concentrations (Conference Presentation)," in Proc.SPIE, 2020, vol. 11258.

[129] New technology may significantly reduce diagnostic time of coronavirus [Online]. Available: https://www.eurekalert.org/pub releases/2020-02/buntm021420.php

[130] X. Tian et al., "Potent binding of 2019 novel coronavirus spike protein by a SARS coronavirus-specific human monoclonal antibody," Emerging microbes \& infections, vol. 9, no. 1, pp. 382-385, Feb. 2020.

[131] H. I. s. writers. (2020, 30 Nov 2020). Treated Fabric with Antiviral and Antibacterial Properties Rapidly Destroys $99.99 \%$ of Coronavirus. Available: $\quad$ https://www.hospimedica.com/covid19/articles/294782850/treated-fabric-with-antiviral-and-antibacterialproperties-rapidly-destroys-9999-of-coronavirus.html

[132] Sensors woven into a shirt can monitor Covid-19 signs: MIT [Online]. Available: $\quad \underline{\text { http://textilefocus.com/sensors-woven-shirt-can-monitor- }}$ covid-19-signs-mit/

[133] N. M. Ferguson et al., "Strategies for mitigating an influenza pandemic," Nature, vol. 442, no. 7101, pp. 448-452, Jul. 2006.

[134] S. Tabik et al., "COVIDGR Dataset and COVID-SDNet Methodology for Predicting COVID-19 Based on Chest X-Ray Images," IEEE Journal of Biomedical and Health Informatics, vol. 24, no. 12, pp. 3595-3605, 2020.

[135] L. Fan et al., "Progress and prospect on imaging diagnosis of COVID19," Chinese Journal of Academic Radiology, vol. 3, no. 1, pp. 4-13, Mar. 2020.

[136] J. Canning, "Livability in a time of Corona: the need for intelligent buildings and real estate", Liknedin Pulse, Jun. (2020) Available: https://www.linkedin.com/pulse/livability-time-corona-need-intelligentbuildings-real-john-canning/ 